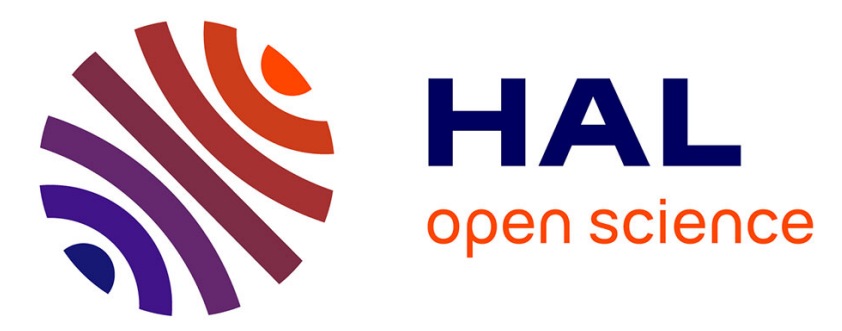

\title{
TEC variations along an East Euro-African chain during 5th april 2010 geomagnetic storm
}

Amira Shimeis, Claudia Borries, Christine Amory-Mazaudier, Rolland Fleury, Ayman Mohamed Mahrous, A.F. Hassan, Samir Nawar

\section{To cite this version:}

Amira Shimeis, Claudia Borries, Christine Amory-Mazaudier, Rolland Fleury, Ayman Mohamed Mahrous, et al.. TEC variations along an East Euro-African chain during 5th april 2010 geomagnetic storm. Advances in Space Research, 2015, 55 (9), pp.2239-2247. 10.1016/j.asr.2015.01.005 . hal-01271473

\section{HAL Id: hal-01271473 \\ https://hal.science/hal-01271473}

Submitted on 14 Apr 2016

HAL is a multi-disciplinary open access archive for the deposit and dissemination of scientific research documents, whether they are published or not. The documents may come from teaching and research institutions in France or abroad, or from public or private research centers.
L'archive ouverte pluridisciplinaire HAL, est destinée au dépôt et à la diffusion de documents scientifiques de niveau recherche, publiés ou non, émanant des établissements d'enseignement et de recherche français ou étrangers, des laboratoires publics ou privés. 


\section{TEC Variations along an East Euro-African Chain}

\section{during $5^{\text {th }}$ April 2010 Geomagnetic Storm}

A.Shimeis ${ }^{1,2,4}$, C.Borries ${ }^{3}$, C. Amory-Mazaudier ${ }^{4,5}$, R.Fleury ${ }^{6}$,A.M. Mahrous ${ }^{2}$,A. F.Hassan ${ }^{2}$, S. Nawar $^{7}$

1. Department of Solar and Space Research, National Research Institute of Astronomy and Geophysics (NRIAG),Helwan ,Egypt.

2. Space Weather Monitoring Center (SWMC), Faculty of Science, Helwan University, Egypt

3. German Aerospace Center (DLR),Institute of Communications and Navigation, Neustrelitz, Germany.

4. Laboratoire de Physique des Plasmas, UMPC Sorbonne Paris, 4 Avenue de Neptune 97107 SaintMaur-des-Fossés, France.

5. T/ICT4D, ICTP, Strada Costiera 11, I - 34151 Trieste Italy.

6. Microwave Department, The School : Telecom-Bretagne of Brest, France

7. Astronomy Department, National Research Institute of Astronomy and Geophysics (NRIAG),Helwan ,Egypt.

The email address of the corresponding author:

amirashimeis@yahoo.com ; amirashimeis@ nriag.sci.eg ; amirashimeis@lpp.polytechnique.fr

\section{Abstract}

In this paper, we analyzed the variations of TEC along a latitudinal East Euro-African chain, during the storm of April 5, 2010. We observed a large asymmetry between the two hemispheres. We detected the presence of a TID in the Northern hemisphere on April 5 .The propagation time of the TID from high to low latitudes and the speed of the TID was 
determined. On April 5, 6 and 7, we observed a decrease of the TEC and changes of the NO+ in the Northern hemisphere. This depletion is caused by the large-scale thermospheric wind disturbances due to Joule heating dissipation in the auroral zone.

Key words. Ionosphere (equatorial ionosphere, ionosphere thermosphere interaction) GPS-TEC; TID; wind; Coronal hole; geomagnetic storm.

\section{Introduction}

In this paper, we contribute to study the geomagnetic storm 05 April 2010 and analyze the signatures of this storm at low and middle latitudes on the Total Electron Content (TEC) and the ionospheric composition. This event was first studied by Möstl et al. (2010) who described the fast interplanetary coronal mass ejection (ICME) which was` observed by STEREO/HI for the full Sun-Earth line and was associated with a magnetic cloud (MC) and a geomagnetic storm at Earth. For the same event, Connors et al. (2011) observed a significant magnetic earthward flux transfer suggested by electric fields using THEMIS spacecraft. The magnetic earthward component of flux transfer manifested in the inner magnetosphere as "over di polarization" signatures at GOES 11 in the midnight sector. Prikryl et al. (2011) focused on the high-latitude 
ionospheric effects including GPS phase scintillation and rapid variations in TEC. They found strong asymmetries of the ionospheric response in the Northern and Southern auroral zones. Wilder et al. (2012) used the thermosphere-ionosphere-mesosphere electrodynamics coupling general circulation model to interpret the intense levels of Joule heating on the dayside and the resulting anomalous thermospheric density enhancements and traveling disturbances. Shimeis et al. (2012) studied the ionosphericmagnetic disturbance of the magnetic storm 05 April 2010 near the crest of the equatorial anomaly and detected the quick arrival of the prompt penetration of the magnetospheric electric field (Vasyliunas, 1970) and the delayed effect of the ionospheric disturbance dynamo (Blanc and Richmond 1980).

Finally, Fathy et al. (2014) analyzed the signature of the planetary ionospheric disturbance dynamo associated to the dissipation of currents that cause the Joule heating during the storm 05 April, 2010. They found the existence of an anti-Sq cell during three days 06-08 April 2010.

The TEC data can be used to determine Traveling Ionospheric Disturbances (TIDs).Katamziand Habarulema, (2013) use two receiver arrays over the South African region, which were along two distinct longitudinal sectors of about $18^{\circ}-20^{\circ}$ and $27^{\circ}-28^{\circ}$. Amplitude and dominant periods of these structures varied between 0.08 -2.16TECU, and 1.07-2.13 h respectively. The wave structures were observed to propagate 
towards the equator with velocities between 587.04 and $1635.09 \mathrm{~m} / \mathrm{s}$. The first investigation of traveling ionospheric disturbances (TIDs) over midlatitude South Africa during the 15 May 2005 severe geomagnetic storm on the South African observed by Ngwira et al., (2012). Borries et al. (2009), made the first statistical analysis of large- scale traveling ionospheric disturbances (LSTID) over Europe TEC data derived from Global Navigation Satellite System GNSS measurements. Equatorward propagating storm-induced wave packets have been identified during several geomagnetic storms. Characteristic parameters such as velocity, wavelength and direction were estimated from perturbation TEC maps. Borries et al. (2009) got a mean wavelength of $2000 \mathrm{~km}$, a mean period of $59 \mathrm{~min}$, and a phase speed of $684 \mathrm{~ms}^{-1}$. The comparison to LSTID observed over Japan shows a similar wavelength but a considerably faster phase speed. This is due to the differences in the distance to the auroral region or inclination/ declination of the geomagnetic field lines.

In this paper, we analyze the variation of the vTEC along the EuroAfrican chain of GNSS receivers during the geomagnetic storm 05 April 2010. We identify TID from GNSS derived TEC and analyze the variation of $\mathrm{NO}+$ at middle and low latitudes. The data sets and data processing will be then presented. Results, discussion, and conclusion will be then shown for this study. 


\section{Data set and Data processing}

The study is performed for tracking the variation of TEC along the latitudinal chain of GNSS stations during the different phases of the geomagnetic storm from 03 to 10 April 2010. Figure 1 shows the location of the stations used in the study. Table 1 gives the geographic latitude and longitude. The daily mean vTEC values are derived from the available GPS data (http://igscb.jpl.nasa.gov/network/list.html and http://www.unavco.org/data/data.html ).

The fundamental GPS frequency is $f_{0}=10.23 \mathrm{MHz}$ from which $f_{1}$ and $f_{2}$ arederived $\left(f_{1}=1575.42 \mathrm{MHz}=154 . f_{0}\right.$ and $f_{2}=1227.60 \mathrm{MHz}=120 . f_{0}$ ), defined the group delay as:

$$
P_{1}-P_{2}=40.3 T E C\left(\frac{1}{f_{1}^{2}}-\frac{1}{f_{2}^{2}}\right) V
$$

$P_{1}$ and $P_{2}$ are the pseudo ranges for $f_{1}$ and $f_{2}$ respectively. By rewriting the equation of group delay, we obtain:

$$
T E C=\frac{\left(P_{1}-P_{2}\right)}{40.3} \frac{f_{1}^{2} f_{2}^{2}}{f_{2}^{2}-f_{1}^{2}}
$$

The TEC between the satellite and the user depends on the satellite elevation angle; this measurement is called Slant TEC (sTEC). The TEC varies temporally and spatially, and depends on the solar activity, user location, and the satellite elevation angle. This measurement is named 
vertical TEC (vTEC). To convert sTEC to vTEC, we used the following equation:

$$
v T E C=\left(s T E C-B_{s}-B_{u}\right)\left(\sqrt{1-\left(\frac{R_{e} \times \cos (\varepsilon)}{R_{e}+h_{s}}\right)^{2}}\right)
$$

$B_{s}$ and $B_{u}$ are the instrumental biases of satellites and receivers respectively; $R_{e}=6371 \mathrm{~km}$ is the mean radius of the Earth; "is the elevation angle of the satellite (Titheridge, 1972).

We used the X-component of solar wind speed Vx with a time resolution of $1 \mathrm{~min}$ and the Bz component of the interplanetary magnetic field IMF with a time resolution of $5 \mathrm{~min}$. These solar wind parameters were recorded by the $\mathrm{ACE}$ satellite (http://www.srl.caltech.edu/ACE/ASC/browse/view_browse_data.html)

We also used the magnetic indices Dst, AU and AL with a time resolution of $1 \mathrm{~min}$ (http://isgi.latmos.ipsl.fr/lesdonne.htm /), see Shimeis et al. (2012) for more details.

In order to characterize the phases of the ionospheric storm, we calculate the rate of change of the vTEC as follows:

$$
\Delta \mathrm{vTEC}=<\mathrm{vTEC}_{\text {quiet }}>-<\mathrm{vTEC}_{\text {storm day }}>
$$

Where: 
$\left\langle\mathrm{vTEC}_{\text {quiet }}\right\rangle: \quad$ The mean arithmetic value of vTEC of the most magnetic quietest days of April 2010 see table 2 (Shimeis et al., 2012).

$<\mathrm{vTEC}_{\text {stomday }}>\quad$ The vTEC observed each day from 03 to 10 April 2010

TID amplitudes have been estimated from the GNSS data, recorded at the above mentioned GNSS stations, according to the procedure described in Borries et al. (2009). Mapping of the TID amplitude data into a regular grid has been skipped because of the lower number of receivers.

In order to characterize the change of composition, we use the data of the SABER observations, which is the NO+(v) volume emission rate (VER). The SABER (Sounding of the Atmosphere using Broadband Emission Radiometry) instrument supports the TIMED ( Thermosphere Ionosphere Mesosphere Energetics and Dynamics)mission objectives to determine the followings:

- Spatial and temporal variations in the density and temperature structure of the mesosphere and lower thermosphere

- Relative importance of various atmospheric heating and cooling mechanisms 
- Roles played by key chemically and energetically important chemical species.

SABER measures the vertical distributions of molecular constituents that are important for their direct role in solar photon energy absorption and their indirect role in chemical reactions involving energetically important chemical species Yee et al., (2013).

\section{Results}

Figure 2 illustrates the time variation of the solar wind speed Vx (panel a), the component $\mathrm{Bz}$ of the interplanetary magnetic field (panel b) and geomagnetic indices Dst (panel c), AU and AL (panel d) during the selected period 03-10 April 2010. On 5 April, Vx (Figure 2a) increased from $500 \mathrm{~km} / \mathrm{s}$ to $700 \mathrm{~km} / \mathrm{sec}$ at the time of the SSC and reached the maximum value at $800 \mathrm{~km} / \mathrm{sec}$ on 13:00 UT. It remained at $600 \mathrm{~km} / \mathrm{sec}$ (on the average) from 6 to 8 April 2010. Vx started to decrease around 18:00 UT on 8 April 2010, to reach $450 \mathrm{~km} / \mathrm{s}$ on 9 April around 12:00UT and increased again up to $500 \mathrm{~km} / \mathrm{s}$ at around 00:00 UT on 10 April 2010. The IMF Bz (Figure $2 b$ ) turned southward with value of $\sim-12 \mathrm{nT}$ at 08:26 UT on 5 April and reached the maximum value of $\sim 19$ nT. It remained negative for several hours until 10:30UT on 5 April 2010, except for several northward excursions until 11:00 UT on 5 April 2010. IMF Bz turned southward again around 11:00 UT and remained negative for one 
day (long time duration) on 6 April 2010, except a round 13:00UT: it exhibits a northward peak. IMF $\mathrm{Bz}$ returned to its quiet values at 03:00UT on 7 April 2010. The Dst index (Figure 2c) increased strongly from $\sim-10 \mathrm{nT}$ to $35 \mathrm{nT}$ at the time of SSC. Then it decreased and had two negative peaks excursions of the same amplitude $\sim-50 \mathrm{nT}$ around 11:00 and at 14:00 UT during the main phase of the storm on 5 April 2010. The Dst reached the minimum value of $\sim 100 \mathrm{nT}$ around 12:00 UT on 6 April 2010. Dst returned to its normal values on 10 April 2010 around 03.00UT. AU and AL indices (Figure 2d) exhibited three main maximum values, on 5 April 2010 at around 08:26 UT (350 nT for AL and $2000 \mathrm{nT}$ for AU), on 6 April around 01:26 UT (350 nT for AL and $1000 \mathrm{nT}$ for AU) and on 7 April 2010 around 17.30 UT (350 nT for AL and 1500 nT for AU). At the SSC time, the increase of the solar wind component Vx from $500 \mathrm{~km} / \mathrm{s}$ to $800 \mathrm{~km} / \mathrm{s}$ (Figure 2a) is combined with the southward amplitude of IMF Bz component (-12) (Figure 2b). At the SSC time, we also can observe the increase of Dst amplitude which reached $\sim 35 \mathrm{nT}$, followed by a decrease to $\sim-50 \mathrm{nT}$ (Figure 2c) and increases of AL and AU indices. All these observations are the effects associated with the coronal mass ejection of 3 April 2010, which reached the Earth on 5 April 2010 Möstl et al., (2010). 
Figure 3 shows the time variation of the vTEC component from April 3 to April 092010 along a latitudinal chain of GPS stations. The vTEC observations (red lines) are superimposed to the magnetic quiet time reference $<\mathrm{vTEC}_{\text {quiet }}>$ (blue lines). On magnetic quiet days 03 and 09 April, the measured vTEC and the $<\mathrm{vTEC}_{\text {quiet }}>$ were matched very well in all stations, except in the equatorial regions and the Southern hemisphere. The measured vTEC is $10 \%$ more than the $\left\langle\mathrm{vTEC}_{\text {quiet }}\right\rangle$ in these stations.

During the initial phase, on 5 April, the recorded vTEC had the maximum value of 50 TECU around $12.00 \mathrm{UT}$ at equatorial latitude (station : NAZR $; 8.6^{\circ}$ ). The vTEC had a maximum value of $\sim 15$ TECU at $\sim 10: 30$ UT at high latitudes, $\sim 35$ TECU at $\sim 11: 30 \mathrm{UT}$ at mid-latitudes, and $\sim 50$ TECU at $\sim 12.30 \mathrm{UT}$ at low-latitudes.

During the recovery phase 6 to 7 April, the vTEC appeared 25\% less than $<\mathrm{vTEC}_{\text {quiet }}>$ in all stations, except in the equatorial regions and the Southern hemisphere stations, where the vTEC is $20 \%$ more than the < vTEC $_{\text {quiet }}$.

Figure 4 represents the latitudinal variation $\triangle \mathrm{vTEC}$ along the EuroAfrican chain of GPS stations during the geomagnetic storm 03-10 April. We observe a TEC enhancement (positive storm effect) at all stations post the SSC time and during the main phase of the storm on 05 April 
2010. At auroral stations, the positive storm effect is $\sim 10 \%$ of the < $\mathrm{vTEC}_{\text {quiet }}>$. At mid-latitudes, the positive storm enhancement is $\sim 100 \%$ of $\left\langle\mathrm{vTEC}_{\text {quiet }}\right\rangle$ and at low latitudes and equatorial regions the increase of TEC is $\sim 200 \%$ of the $<\mathrm{vTEC}_{\text {quiet }}>$. Negative storm effects, i.e. ionization depletions, occurred at all stations after the enhancements. Transient TEC depletions with a maximum depletion of $10 \%$ of the $\left\langle\mathrm{vTEC}_{\text {quiet }}\right\rangle$ occurred during the main phase at 16:30 UT on 05 April at station (SODA; 67.4). It then extended to mid-low latitude stations. The start time of the effect was tracked along the latitudinal chain of stations and is marked by downward directed arrows in Fig. 4. During the recovery phase 6-7 April, the negative $\Delta$ vTEC effects persisted for 2 days at all the stations except in the equatorial regions and the Southern hemisphere stations.Figure 4 illustrates the amplitude of $\triangle$ vTEC. $\triangle$ vTEC increases from high to low latitudes. The increase of $\triangle \mathrm{vTEC}$ is $\sim 10 \%$ of $\left\langle\right.$ vTEC $_{\text {quiet }}>$ at high latitudes, $100 \%$ at middle latitudes and $200 \%$ at low latitudes.

Figure 5 shows the hourly variation of vTEC for selected stations along Euro-African chain of GPS on 5 April 2010. The black vertical line indicates the SSC and the red arrow represents the positive phase of the ionospheric storm in each station. The positive phase of the ionospheric storm occurred at $10.26 \mathrm{UT}$ at $\mathrm{CNIV}$ (first red line) and at $12.35 \mathrm{UT}$ at 
HELW (second red line). This is equivalent to the time delay between CNIV and HELW is 02:09 hours. As the longitudinal distance is about $3300 \mathrm{~km}$, the speed in North-South direction is approximately $310 \mathrm{~m} / \mathrm{s}$. The time delay between SMLA and HELW is about 60 minutes, resulting in a speed of $610 \mathrm{~m} / \mathrm{s}$. The time delay between MIKL and HELW is about 30 minutes resulting in a speed of $1038 \mathrm{~m} / \mathrm{s}$ and the time delay between NICO and HELW is about 15 minutes resulting in $610 \mathrm{~m} / \mathrm{s}$. Therefore, the mean propagation speed is $642 \mathrm{~m} / \mathrm{s}$ with a large standard deviation.

Figure 6 shows the TID amplitudes estimated from the vTEC on 05 April 2010. Blue color indicates a negative TID amplitude and red color positive amplitude. The black line marks the passing TID. The slope of this line gives the speed of the TID. The speed of the TID during this storm is $500 \mathrm{~m} / \mathrm{s}$.

Figure 7 shows the SABER observations of the $\mathrm{NO}^{+}(\mathrm{v})$ volume emission rate (VER) along the geographical latitude on $\mathrm{x}$-axis with altitude (yaxes) for some days around the geomagnetic storm of 05 April 2010 measured by SABER. The days 04, 08 and 09 April are quiet days in which $\mathrm{NO}^{+}$has a normal distribution. The figures do not show any disturbance nor high values for $\mathrm{NO}^{+}$at all latitudes. The days 05,06 and 
07 April are most disturbed and the distribution change of $\mathrm{NO}^{+}$is observed. There is an increase of $\mathrm{NO}^{+}$at high and low latitudes.

We represent in figure 7 the variation of the $\left.\mathrm{NO}^{+(} \mathrm{v}\right)$, related to auroral electric fields which influence low latitudes. At the altitudes from $110 \mathrm{~km}$ and $160 \mathrm{~km}$, the auroral electric fields significantly influence densities, temperatures, and composition in the ionosphere (e.g. Rodger et al. (1992)). These electric fields drive the ionospheric plasma through the neutral atmosphere and cause intense ion frictional heating. The resulting high ion temperatures can drastically modify ion chemical reaction rates and generally favor conversion of $\mathrm{O}^{+}$to $\mathrm{NO}^{+}$(McFarland et al. (1973); Torr et al. (1977); St.-Maurice and Torr (1978); and St.-Maurice and Laneville(1998))

$$
\mathrm{O}^{+}+\mathrm{N}_{2} \rightarrow \mathrm{NO}^{+}+\mathrm{N} \quad \text { (4.17) through the reaction: }
$$

This acts to raise the molecular to atomic ion transition altitude (where the plasma is composed of $50 \% \mathrm{O}+$ and $50 \%$ molecular ions) above its quiescent value. These changes of the $\mathrm{NO}^{+}$are due to auroral electric fields starts at high latitude and extend to low latitude. Such a rapid expansion may then cause a significant upwelling of the neutral atmosphere (i.e. the motion of air through constant pressure surfaces), causing the depletion of the atom-to-molecule ratio as air of different composition is raised to higher altitudes. This change in the chemical 
composition causes an increased recombination in the ionosphere and a reduction in the ionization concentration. Rapid heating and expansion of the atmosphere at high latitudes result in pressure gradients, which, in turn, modify the global thermospheric circulation, producing enhanced equatorward winds (Richmond and Matshusita (1975); and Richmond and Roble (1979)). The storm-induced equatorward wind in turn transport the composition changes to middle latitudes, again causing a reduction in the level of ionization (E. Yizengaw et al. (2005)). These effects are shown in figures 3,4 and 7.

\section{Discussion}

Figure 2 illustrates the general geophysical context of this event. A CME hits the Earth on April 052010 producing the starting point of a storm SSC. High speed solar wind streams due to a coronal hole reach the Earth on 06 and 07 April. We analyzed the effects of this event on the TEC variations along a latitudinal chain of GPS stationsstations between 20 and 40-degree longitudes, from Northern to Southern high latitudes.

An increase of the TEC (positive storm) on 05 April 2010 is observed in figure 3 for all stations. A decrease of the TEC (negative storm) is observed only in the Northern hemisphere during two days 06-07 April 2010. There is no negative variation of TEC in the equatorial and 
Southern stations. This fact illustrates the strong hemispheric asymmetry of this storm at equinox related to several factors to 1) Solar activity, 2) Atmospheric dynamo, and 3) Difference between the geographic and geomagnetic axis, previously found by Prikryl et al. (2011). The precipitating particle energy or Joule heating at the auroral regions give rise to TID (Millward et al. (1993)), which propagates equatorward. Balthazor and Moffett (1997) have studied in details the propagation of TIDs to equatorial latitudes. The equatorward propagation of such TIDs is clearly visible on GPS TEC data recorded during the magnetic storm on 05 April 2010 as shown in figures 3, 4, 5, 6 and 7. The time of appearance of the TEC disturbance varies with latitudes (as shown in figures 3,4 ,and5). The time delay between high and low latitudes is $\sim 2: 09 \mathrm{~h}$ (figure 5). Such delay can be explained by the TID propagation as mentioned in Borries et al. (2009). The mean speed of $642 \mathrm{~ms}^{-1}$ is comparable to TID speed. Blanc and Richmond (1980) showed that another process the ionospheric disturbance dynamo can be invoked to explain the TEC variations. This process can affect low latitudes after 2 or 3 hours. Mazaudier and Bernard (1985) analyzed the time arrival of the atmospheric wind disturbance at middle latitude for several storms and found a time delay of several hours. Fejer et al, 1983 measured the equatorial disturbance dynamo electric fields with the Jicamarca radar. 
Sastri, 1988showed the decrease of the F2 layer associated to the ionospheric disturbance dynamo during several days. Shimeis et al. (2012) and Fathy et al. (2014) analyzed the impact of the ionospheric disturbance dynamo associated to the storm 05 April 2010 on magnetic observations. They found a time delay between the impact of the CME and the effects of ionospheric disturbance dynamo at low latitudes of several hours. This process, which can last several days, clearly appears in figure 4 with a gray shadow. As the speed of the southward extension of vTEC enhancement agrees roughly with the estimated speed of the TID in figure 6 , this enhancement seems to be caused by the TID.

\section{Conclusion}

In this study, we use a latitudinal chain of GPS stations in order to analyze the TEC variations during the 05 April storm. The following results were found:

1- On 05April 2010, the vTEC increases from high to low latitudes. Its amplitude is $\sim 15 \mathrm{TECU}$ at $\sim 10: 30 \mathrm{UT}$, at high latitudes , $\sim 35$ TECU at $\sim 11: 30 \mathrm{UT}$ at mid-latitudes, and $\sim 50$ TECU at $\sim 12: 30$ UT at low-latitudes.

2- The positive storm is observed at all stations after the SSC. At auroral stations, the positive storm effect is $\sim 10 \%$ of the $<$ $\mathbf{v T E C}_{\text {quiet }}>$. At mid-latitudes, the positive storm enhancement is $\sim 100 \%$ of $<\mathbf{v T E C}_{\text {quiet }}>$ and at low latitudes and equatorial regions 
the increase of $\Delta$ vTEC is $\sim 200 \%$ of the $<\mathbf{v T E C}_{\text {quiet }}>$. Negative storm effects, i.e. ionization depletions, occurred at all stations after the enhancements, except at the equator and in the Southern hemisphere.

3- The negative $\Delta$ vTEC effects persisted for 2 days at all the stations except in the equatorial regions and the south hemisphere stations. The decrease of the TEC during 2 days is explained by the effect of the ionospheric disturbance dynamo process which is acting during several days after the SSC (Fathy et al. (2014)).

4- The time lag for the propagation of the TID from high to low latitude is $\sim 02: 09$ hours.

5- The speed of a TID observed during this storm is estimated with $500 \mathrm{~ms}^{-1}$.

6- The changes of the $\mathrm{NO}^{+}$distribution are related to auroral electric fields which influence low latitudes.

Our TEC data shows the strong asymmetry between the two hemispheres, with a propagation of a TID in the Northern hemisphere and the existence of the ionospheric disturbance dynamo effect during several days in the Northern hemisphere.

The next work will be the modeling of this case study. 


\section{Acknowledgements}

Our sincere thanks go to all members of Department of Solar and Space Research, National Research Institute of Astronomy and Geophysics (NRIAG) and the Space Weather and Monitoring Center (SWMC), Helwan University for their ceaseless support. The CFCC PhD program is financially supported by the French-Egypt scientific year project that cooperates with the Department of Scientific and Technological Cooperation Embassy of France in the Arab Republic of Egypt French Institute of Egypt, LPP/Polytechnique/ UPMC/CNRS, NRIAG and Telecom Bretagne-Brest University. A SCINDA GPS station was deployed in EGYPT under the ISWI (International Space Weather Initiative) project which follows the IHY (International Heliophysical Year) project. Our huge thanks go to the great efforts of the coordinators from all organizations (SWMC, Helwan University, CFCC, French-Egypt scientific year project, LPP/Polytechnique/UPMC/CNRS, Brest University, ISWI, and IHY). 


\section{References}

Balthazor, R. L. and Moffett, R. J.A study of atmospheric gravity waves and travelling ionospheric disturbances at equatorial latitudes.Ann. Geophys., 15, 1048-1056, 1997, SRef-ID: 1432-0576/ag/1997-15-1048, 1997.

Connors, M., Russell, C. T. and Angelopoulos, V. Magnetic flux transfer in the 5 April 2010 Galaxy 15 substorm: an unprecedented observation. Ann. Geophys., 29, 619-622, 2011, doi:10.5194/angeo-29-619-2011, 2011.

Fathy, I., C. Amory-Mazaudier, A. Fathy, A. M. Mahrous, K. Yumoto, and E. Ghamry.Ionospheric disturbance dynamo associated to a coronal hole: Case study of 5-10 April 2010. J. Geophys. Res. SpacePhysics, 119, doi:10.1002/2013JA019510, 2014.

Fejer et al., On the Equatorial disturbance dynamo electric fields (GRL vol 10, nº7, 537-540, 1983.

Guglielmino, F., C. Bignami, A. Bonforte , P. Briole, F.Obrizzo , G. Puglisi, S.Stramondo, U. Wegmüller, Analysis of satellite and in situ ground deformation data integrated by the SISTEM approach: The April 
3, 2010 earthquake along the Pernicana fault (Mt. Etna - Italy) case study, Earth and Planetary Science Letters 312 (2011) 327-336, doi:10.1016/j.epsl.2011.10.028, 2011.

Kinrade, J., C. N. Mitchell, P. Yin, N. Smith, M. J. Jarvis, D. J. Maxfield, M. C. Rose, G. S. Bust, and A. T. Weatherwax, Ionospheric scintillation over Antarctica during the storm of 5-6 April 2010,Journal of Geophysical Research, VOL. 117, A05304, doi:10.1029/2011JA017073, 2012.

Katamzi Z.T. , J.B. Habarulema ,"Traveling ionospheric disturbances observed at South African midlatitudes during the 29-31 October 2003 geomagnetically disturbed period" ,Advances in Space Research, Volume 53, Issue 1, p. 48-62, 2013.

Kleimenova, N.G., N.R. Zelinskii, O.V. Kozyreva, L.M. Malysheva, A.A. Solov'ev, Sh.R. Bogoutdinov, Pc3 Geomagnetic Pulsations at Near_Equatorial Latitudes at the Initial Phase of the Magnetic Storm of April 5, 2010, Geomagnetism and Aeronomy, 2013, Vol. 53, No. 3, pp. 313-320, 2013. 
Marubashi, K., and R. P. Lepping, Long-duration magnetic clouds: A comparison of analyses using torus- and cylinder-shaped flux rope models, Ann. Geophys., 25, 2453-2477, 2007.

Mazaudier, C., and Bernard, R., Saint-Santin Radar observations of lower thermospheric storms, Journal of Geophysical Research, VOL. 90, NO. A3, PAGES 2885-2895, MARCH 1, 1985.

McFarland, M., Albritton, D. L., Fehsenfeld, F. C., Ferguson, E. E., and Schmeltekopf, A. L., Flow-drift technique for ion mobility and ionmolecule reaction rate constant measurements. II. Positive ion reactions of $\mathrm{N}+, \mathrm{O}+$, and $\mathrm{H}+2$ with $\mathrm{O} 2$ and $\mathrm{O}+$ with $\mathrm{N} 2$ from thermal to $\sim 2 \mathrm{eV}, \mathrm{J}$. Chem. Phys., 59, 6620-6628, 1973.

Millward, G. H., Moffett, R. J., and Quegan, S, Effects of an atmospheric gravity wave on the midlatitudeionospheric F layer, J. Geophys. Res., 98, 19 173-19 179, 1993.

Möstl, C., M. Temmer, T. Rollett, C. J. Farrugia, Y. Liu, A. M. Veronig, M. Leitner, A. B. Galvin, and H. K. Biernat, STEREO and Wind observations of a fast ICME flank triggering a prolonged geomagnetic 
storm on 5-7 April 2010, Geophys. Res. Lett., 37, L24103, doi:10.1029/2010GL045175, 2010.

Ngwira C.M., L.-A.McKinnell, P.J. Cilliers, E. Yizengaw,An investigation of ionospheric disturbances over South Africa during the magnetic storm on 15 May 2005, Advances in Space Research 49 (2012) 327-335,doi:10.1016/j.asr.2011.09.035, 2012.

Prikryl, P., L. Spogli, P. T. Jayachandran, J. Kinrade, C. N. Mitchell, B. Ning, G. Li, P. J. Cilliers, M. Terkildsen, D. W. Danskin, E. Spanswick, E. Donovan, A. T. Weatherwax, W. A. Bristow, L. Alfonsi, G. De Franceschi, V. Romano, C. M. Ngwira, and B. D. L. Opperman, Interhemispheric comparison of GPS phase scintillation at high latitudes during the magnetic-cloud-induced geomagnetic storm of 5-7 April 2010, Ann. Geophys., 29, 2287-2304, 2011, doi:10.5194/angeo-292287-2011, 2011.

Richmond, A.D., S. Matsushita, Thermospheric response to a magnetic storm (1975), Journal Geophys.Res.Vol 80, No.19, 2839-2850, 1975.

Richmond, A., and R. G. Roble, Dynamic effects of aurora generated gravity waves on the mid-latitude ionosphere, J. Atmos. Terr. Phys., 41, 
$841-852,41,1979$.

Rodger, A. S., Moffett, R. J., and Quegan, S., The role of ion drift in the formation of ionisation troughs in the mid- and high-latitude ionosphere - A review, J. Atmos. Terr. Phys., 54, 1-30, 1992.

Sastri, J.H, Equatorial electric field of Ionospheric disturbance dynamo origin ,Annalesgeophysiace 1988, 6, (6), 635-642.

Shimeis, A., I. Fathy, C. Amory-Mazaudier, R. Fleury, A. M. Mahrous, K. Yumoto, and K. Groves, Signature of the coronal hole near the north crest equatorial anomaly over Egypt during the strong geomagnetic storm 5 April 2010, J. Geophys. Res., 117, A07309, doi:10.1029/2012JA017753, 2012.

St.-Maurice, J.-P.andTorr, D. G., Nonthermal rate coefficients in the ionosphere - The reactions of $\mathrm{O} /+$ / with $\mathrm{N} 2, \mathrm{O} 2$, and $\mathrm{NO}$, J. Geophys. Res., 83, 969-977, doi:10.1029/JA083iA03p00969, 1978.

St.-Maurice, J.-P., Cussenot, C., and Kofman, W., On the usefulness of E region electron temperatures and lower $\mathrm{F}$ region ion temperatures for the extraction of thermospheric parameters: a case study, Ann. Geophys., 17, 1182-1198, 1999. 
Wilder, F. D., G. Crowley, B. J. Anderson, and A. D. Richmond, Intense dayside Joule heating during the 5 April 2010 geomagnetic storm recovery phase observed by AMIE and AMPERE, J. Geophys. Res., 117, A05207, doi:10.1029/2011JA017262, 2012.

Yee J., E. R. Talaat, A. B. Christensen, T. L. Killeen, J. M. Russell III, and T. N. Woods, TIMED Instruments, Johns Hopkins APL Technical Digest, Volume 24, Number 2 ,2003. 


\section{Table Captions}

Table 1 Latitude and Longitude Station Chain

Table 2 List of the most magnetic quiet days of April 2010 determined with the Am indices 


\section{Figure Captions}

Figure 1 Euro-African Chain GPS stations applied for data acquisition

Figure2The solar wind parameters and geomagnetic indices for strong storm from 3 to 10 April 2010: (a) the Vx component of the solar wind speed, (b) the Bz component of the interplanetary magnetic field, (c and d) the Dst index and the AU and AL indices.(Shimeis et al. 2012).

Figure3Daily variations of vertical total electron content (vTEC) for the Euro-African latitudinal chain of GPS stations. Right side panel contents the stations from SODA to NICO. Left side panel shows the station from HELW to SYOG. The blue line corresponds to the magnetic quiet time variation and the red line to the geomagnetic stormed interval days.

Figure 4 Latitudinal variation of $\triangle \mathrm{VTEC}$ along the Euro-African chain of GPS stations during the geomagnetic storm. The red line indicate to the Storm Sudden Commencement SSC.

Figure 5 the hourly variation of vTEC of selected stations along EuroAfrican chain of GPS during the stormed day 5 April 2010. The blackline 
indicates the SSC and the red arrow represents the positive phase of the ionospheric storm in each station.

Figure 6 the latitudinal variation of vTEC of Euro-African chain of GPS stations during the geomagnetic storm. The sold black line represents the Traveling ionosphric disturbance (TID).

Figure7 shows the NO+(v) volume emission rate (VER) along the geographical latitude on $\mathrm{x}$-axis with altitude (y-axes) for each day of the geomagnetic storm of 05 April 2010 measured by SABER. 
Table 1

\begin{tabular}{|c|c|c|c|c|}
\hline & $\begin{array}{c}\text { Longitude } \\
\left(^{\circ}\right)\end{array}$ & $\begin{array}{c}\text { Latitute } \\
\left(^{\circ}\right)\end{array}$ & $\begin{array}{l}\mathrm{D} \\
\left({ }^{\circ}\right)\end{array}$ & $\begin{array}{c}\mathrm{I} \\
\left({ }^{\circ}\right)\end{array}$ \\
\hline SODA & 26.39 & 67.42 & 10.528 & 77.281 \\
\hline SVTL & 29.781 & 60.533 & 9.586 & 73.767 \\
\hline MOBN & 36.57 & 55.115 & 9.569 & 70.775 \\
\hline CNIV & 31.31 & 51.52 & 7.146 & 67.975 \\
\hline POLV & 34.54 & 49.6 & 7.247 & 66.696 \\
\hline SMLA & 31.87 & 49.2 & 6.651 & 66.223 \\
\hline MIKL & 31.97 & 46.97 & 6.14 & 64.384 \\
\hline EVPA & 33.16 & 45.22 & 5.934 & 62.92 \\
\hline KTVL & 33.97 & 44.39 & 5.863 & 62.214 \\
\hline TUBI & 29.451 & 40.787 & 4.699 & 58.251 \\
\hline ANKR & 32.76 & 39.89 & 4.917 & 57.567 \\
\hline NICO & 33.37 & 35.17 & 4.33 & 51.978 \\
\hline ALX2 & 29.9109 & 31.197 & 3.726 & 45.899 \\
\hline
\end{tabular}




\begin{tabular}{|c|c|c|c|c|}
\hline RAMO & 34.7631 & 30.5978 & 3.907 & 45.703 \\
\hline HELW & 31.33 & 29.85 & 3.708 & 44.006 \\
\hline ALWJ & 36.37 & 26 & 3.516 & 38.4 \\
\hline JEDD & 39.63 & 21.36 & 2.996 & 30.304 \\
\hline NAMA & 42.04 & 19.21 & 2.581 & 26.401 \\
\hline JIZN & 42.1 & 16.69 & 2.336 & 20.974 \\
\hline ASMA & 38.91 & 15.33 & 2.551 & 17.1 \\
\hline NAZR & 39.29 & 8.57 & 1.809 & 0.857 \\
\hline MAL2 & 40.194 & -2.996 & -0.828 & -26.893 \\
\hline TANZ & 39.2 & -6.76 & -2.13 & -35.257 \\
\hline TUKC & 33.75 & -9.33 & -2.271 & -42.224 \\
\hline SYOG & 39.584 & -69.007 & -49.649 & -63.578 \\
\hline
\end{tabular}

http://www.geomag.nrcan.gc.ca/calc/mfcal-eng.php 
Table 2:

\begin{tabular}{|l|l|l|l|l|l|l|l|}
\hline Quiet & $\mathrm{i}=1$ & $\mathrm{i}=2$ & $\mathrm{i}=3$ & $\mathrm{i}=4$ & $\mathrm{i}=5$ & $\mathrm{i}=6$ & $\mathrm{i}=7$ \\
days & April & April & April & April & April & April & April \\
13 & 16 & 18 & 25 & 26 & 28 & 30 \\
\hline $\begin{array}{l}\text { Daily } \\
\text { <Am > }\end{array}$ & 4 & 4 & 2 & 3 & 2 & 4 & 4 \\
\hline
\end{tabular}




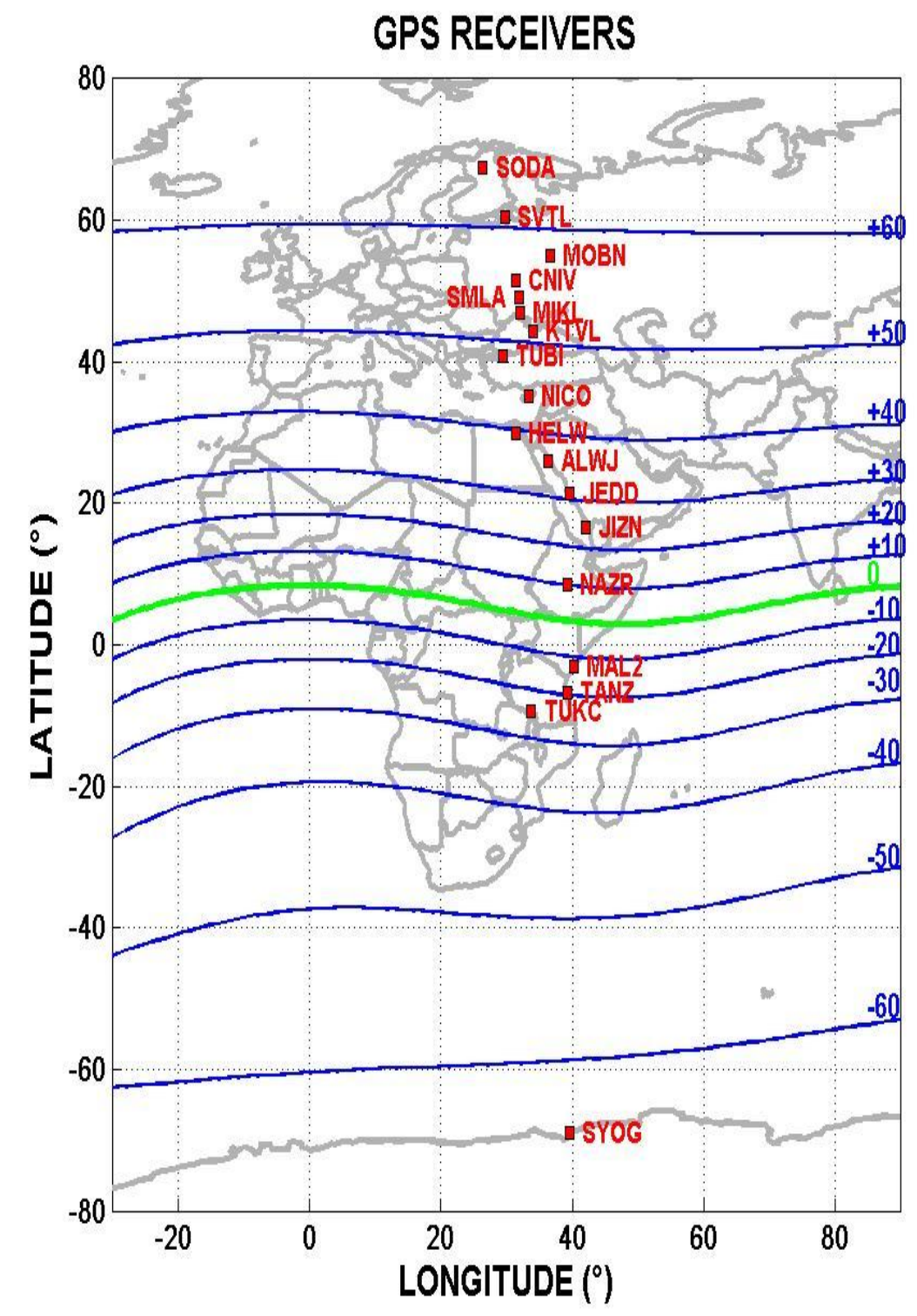

Figure 1 


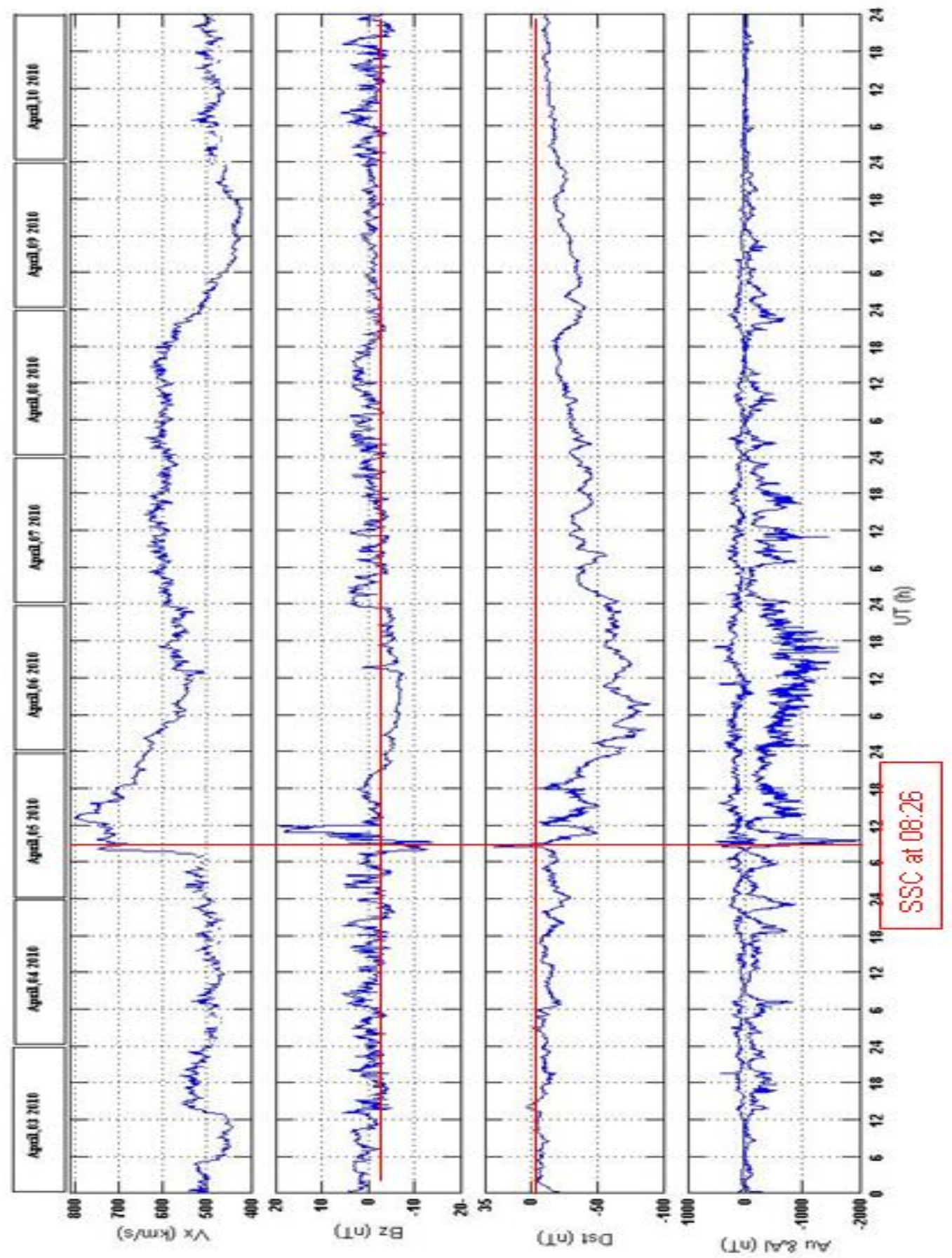

Figure 2 

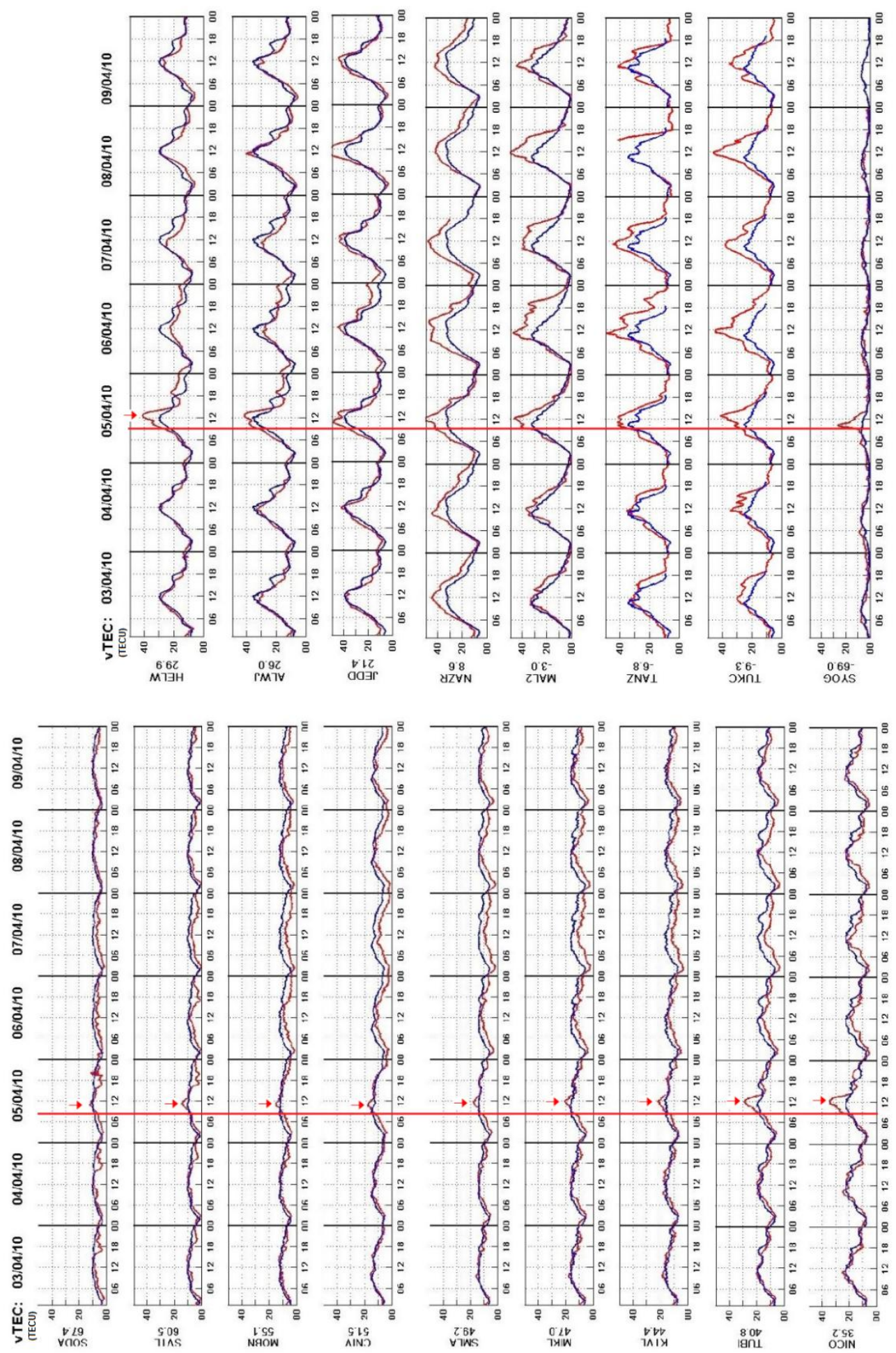

Figure 3 


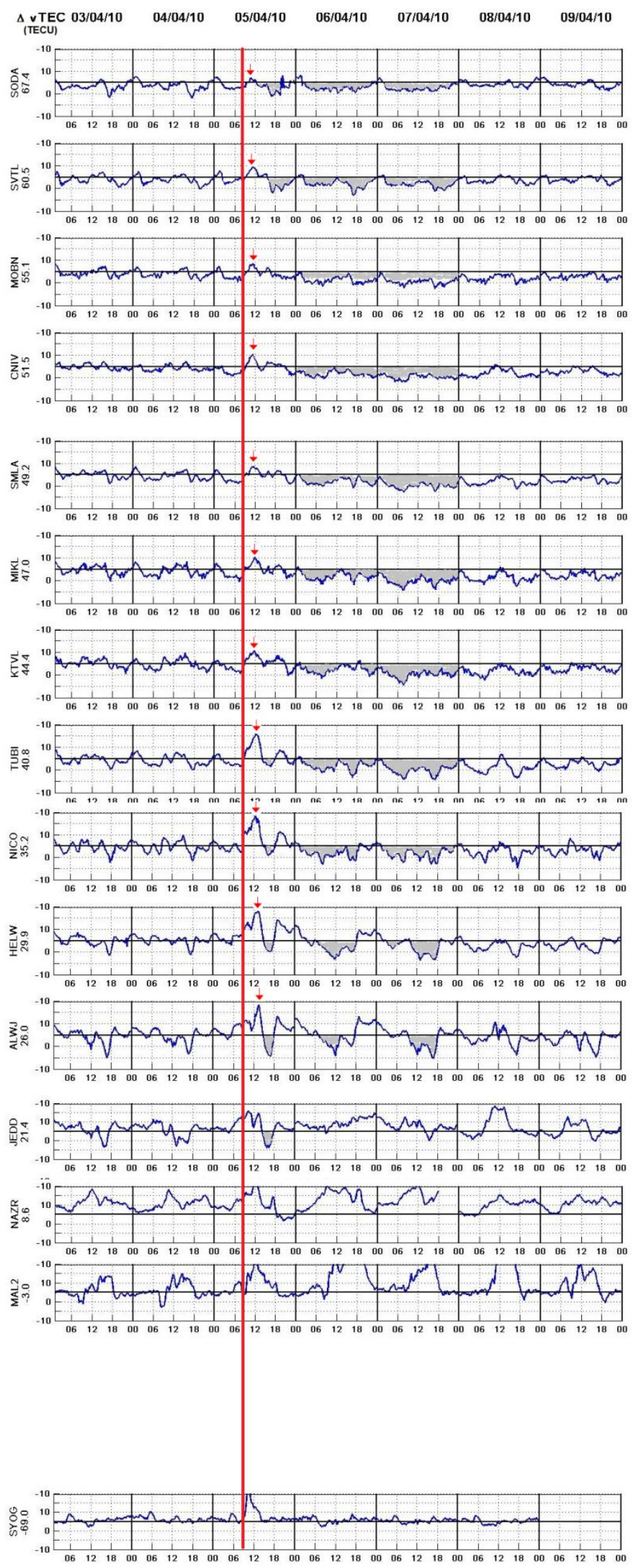

Figure 4 


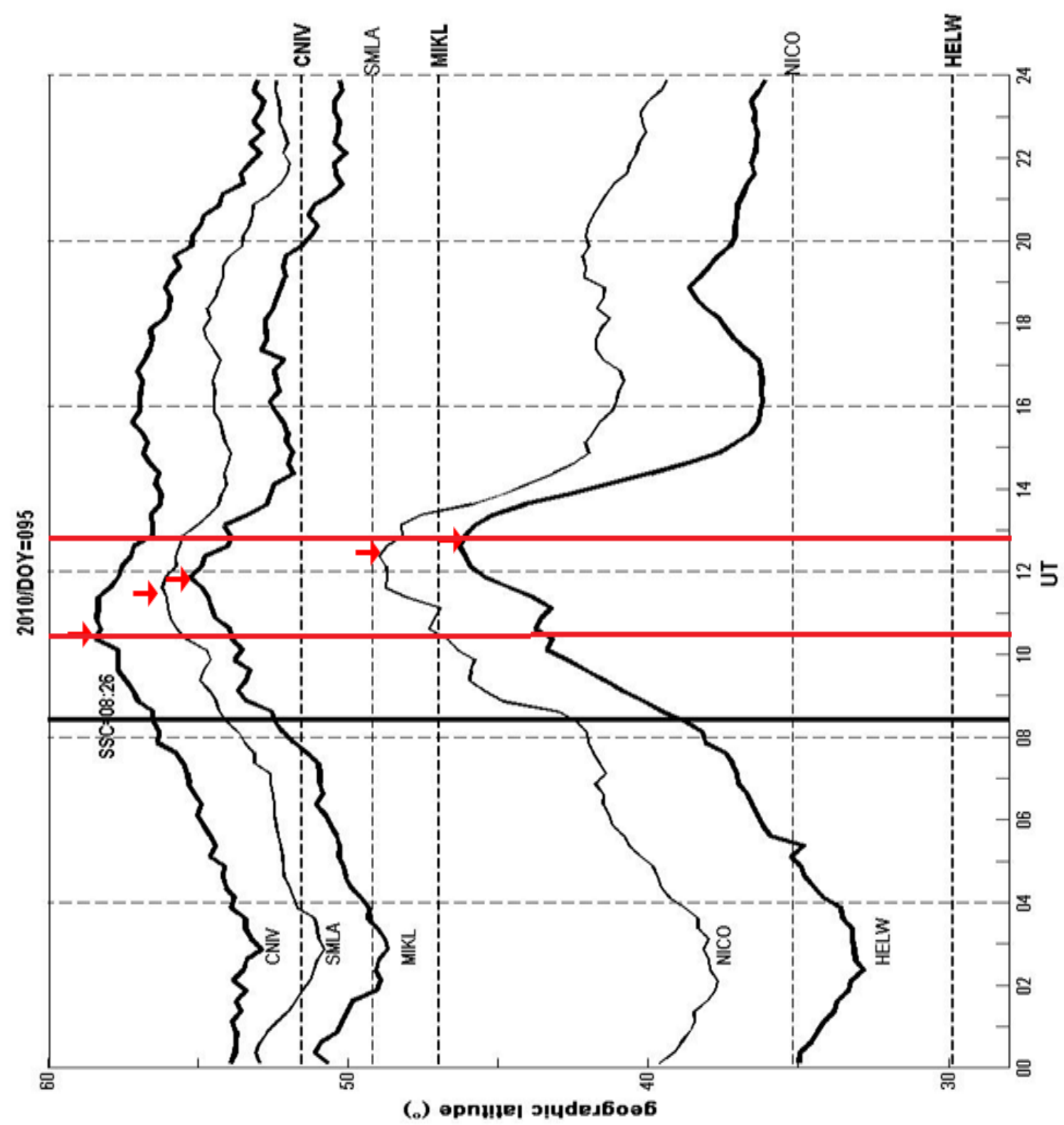


Figure 5 


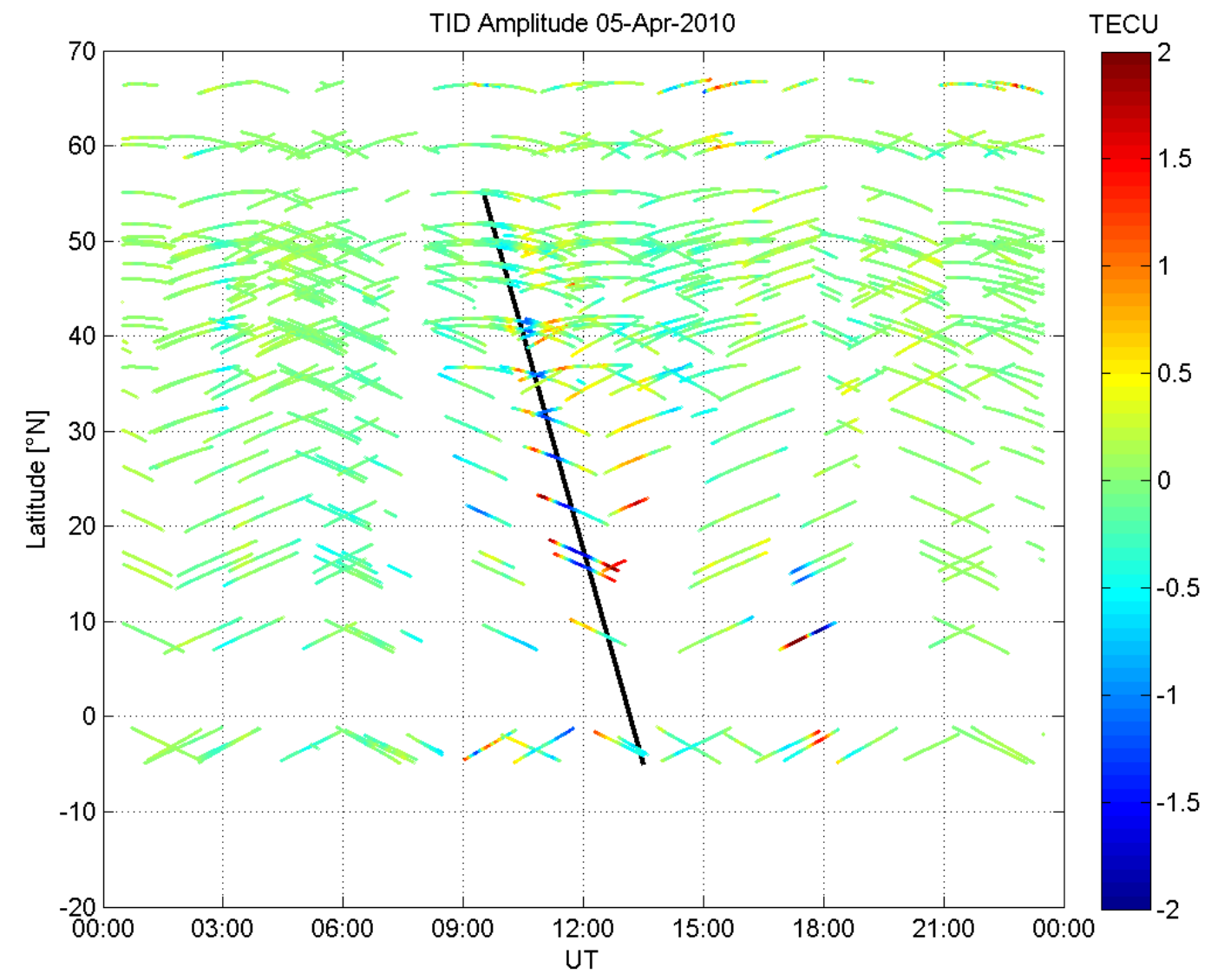

Figure 6 

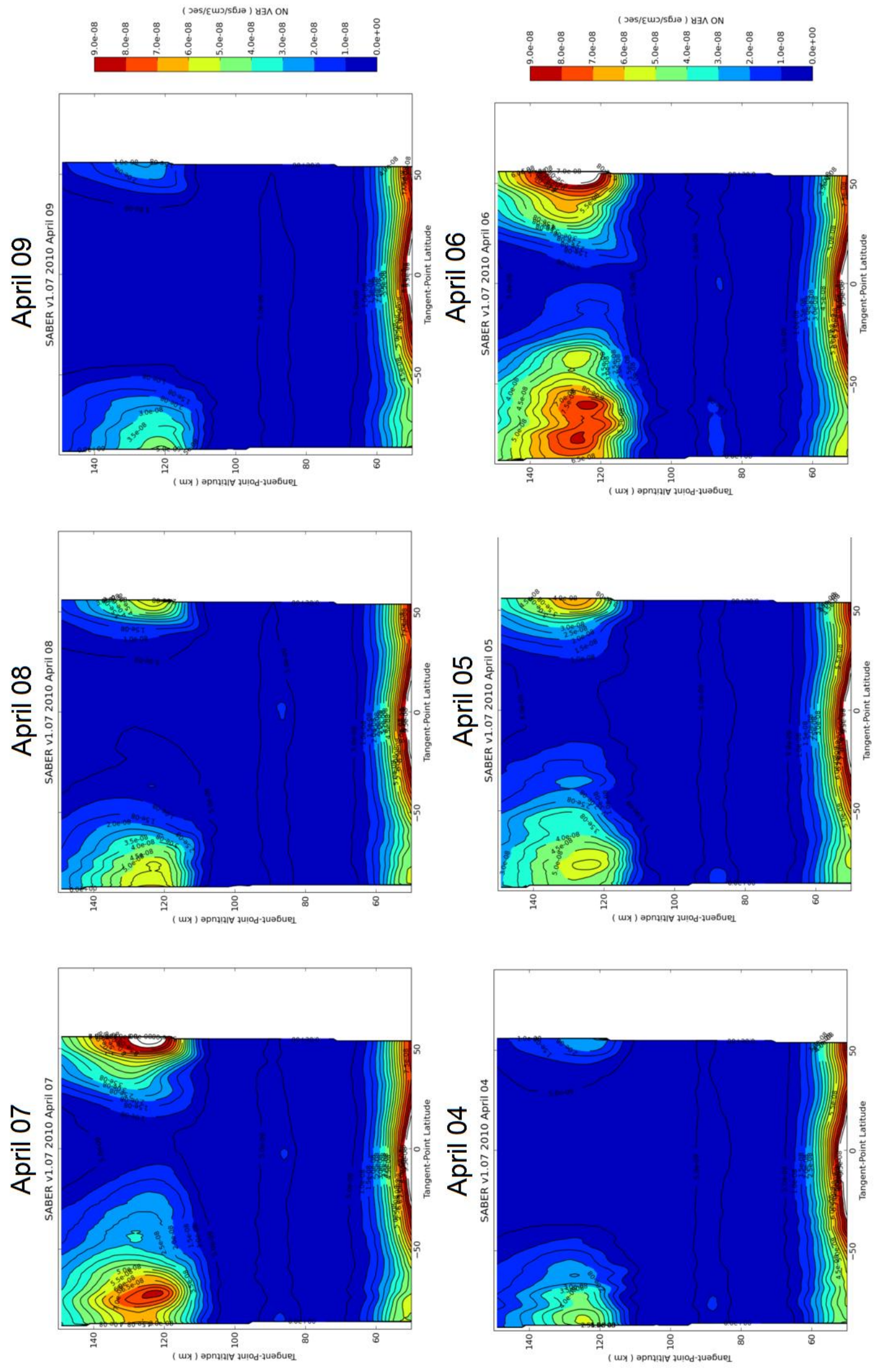

Figure 7 
